\title{
PET Scanner 2D Mode
}

National Cancer Institute

\section{Source}

National Cancer Institute. PET Scanner 2D Mode. NCI Thesaurus. Code C94949.

A measuring process with shielding septa restricting detectors' coincidences. It is generally referred to as simply 2D. 